\title{
Accumulation of essential oils in relation to root differentiation in Angelica archangelica $L$.
}

\author{
G. Pasqua, B. Monacelli, A. Silvestrini \\ Dipartimento di Biologia Vegetale, Università degli Studi di Roma "La Sapienza", Rome, Italy
}

C2003, European Journal of Histochemistry

The accumulation of essential oils in Angelica archangelica subsp. archangelica roots at different developmental stages was investigated through histochemical and chemical analyses. Roots less than $1 \mathrm{~mm}$ in diameter showed a primary diarch structure and two primary secretory ducts in the pericycle. These ducts were ephemeral and probably became dysfunctional early on. Oil accumulation was observed only in the secondary secretory ducts formed by cambium activity and located in the secondary phloem. Gas chromatographic analyses revealed that only taproots exceeding 5 $\mathrm{mm}$ in diameter contained a high concentration of $\alpha$ - and $\beta$ phellandrene, which appreciably influence the oil's aroma.

Key words: Angelica archangelica, essential oils, histochemistry, root differentiation, secretory ducts.

Correspondence: Dr. Gabriella Pasqua, Dipartimento di Biologia Vegetale, Università “La Sapienza”,

P.le Aldo Moro 5, 00185 Rome, Italy.

Fax: international +39.06.49912414.

E-mail: gabriella.pasqua@uniroma1.it

Paper accepted on November 8, 2002

European Journal of Histochemistry 2003; vol. 47 issue 1 [Jan-Mar]:87-90
A ngelica archangelica L. (Apiaceae), a herbaceous biennial plant, grows in damp places in northern and eastern Europe and is commonly used in folk medicine as a remedy for nervousness, insomnia, stomach and intestinal disturbances, and arthritis. The plant is generally cultivated for its roots, which are richer in oils than the other organs and whose oil is esteemed for its use in flavouring and in making perfumes (Klouwen and Ter Heide, 1965).

The aroma constituents of Angelica root oil have been investigated by Taskinen and Nykänen (1975), Forsén (1979), Nykänen et al. (1991), Kerrola et al. (1994), Kerrola and Kallio (1994), and Doneanu and Anitescu (1998). The bulk of the oil (up to $88 \%$ ) consists of monoterpene hydrocarbons, which are responsible for the oil's aroma (Forsén, 1979).

The relative amounts of monoterpene hydrocarbons have been found to vary, and this variability depends on a number of parameters, such as the variety of Angelica archangelica, the maturity of the plant, the extraction methods, and the analytical procedures (Klouwen and Ter Heide, 1965; Taskinen and Nykänen 1975; Forsén, 1979, Kerrola et al., 1994).

In the present study, the chemical composition of essential oils in Angelica archangelica subsp. archangelica was investigated in relation to the developmental stage of the root. The relationship between the synthesis and accumulation of essential oils and the differentiation of different types of secretory ducts was also studied.

\section{Materials and Methods}

\section{Plant material}

Seeds of Angelica archangelica L. subsp. archangelica were soaked in tap water for $48 \mathrm{~h}$ and then sown in seedling trays, in July. The seedlings (0.5-1 $\mathrm{cm}$ in height) were transplanted in $7.5 \mathrm{~L}$ plastic pots containing commercial soil and placed in open 
field at the Botanical Garden of the University of Rome "La Sapienza". The plants showed a beetlike taproot with numerous thin lateral roots. The roots were harvested from 15-month-old plants.

\section{Histologic and histochemical analyses}

Samples of lateral roots $(0.5-2 \mathrm{~mm}$ in diameter) and taproot (3-6 mm in diameter) were fixed in formalin-aceto-alcohol (FAA: $70 \%$ ethanol: glacial acetic acid: formalin, 18:1:1 by volume). The roots were then dehydrated, embedded in paraffin (melting point $56^{\circ} \mathrm{C}$ ), sectioned at $10 \mu \mathrm{m}$ with a standard rotary microtome, and stained with methylene-green and ruthenium-red (Johansen, 1940). To detect essential oils and to study the differentiation of secretory tissues, samples of fresh roots were embedded in agar $(4 \%)$, and sectioned $(50 \mu \mathrm{m})$ with a vibratome (T.P.I. series 1000). The sections were stained with nadi reagent (solution prepared at the time of use, mixing $0.5 \mathrm{~mL}$ of a $1 \% \alpha$-naphtol solution in $40 \%$ alcohol with $0.5 \mathrm{~mL}$ of $1 \%$ dimethyl-p-phenylenediamine chloride in water and with $49 \mathrm{~mL}$ of phosphate buffer $0.05 \mathrm{M}$ (pH 7.2), which stained terpenic compounds in violet (David and Carde, 1964). The sections were immersed in nadi reagent for one hour before examination by light microscopy.

\section{Chemical analyses}

For the detection of essential oils, fresh roots of 1-2 mm, 3-4 mm, and greater than $5 \mathrm{~mm}$ in diameter were used. For each sample, hydrodistillation of $3 \mathrm{~g}$ of f.w. was performed using a microdistillation unit developed by Bicchi et al. (1983).

GC analyses were carried out on a single injection/dual column/dual FID detection/personal computer system (Carlo Erba Mega 5360 GC). Carrier gas: hydrogen; flow-rate: $1.5 \mathrm{~mL} / \mathrm{min}$. Injection: split; split ratio: 1:30; temperature $230^{\circ} \mathrm{C}$. Detector: FID; temperature: $250^{\circ} \mathrm{C}$. Column 1 : HTS-FS OV-1 (25 m $\times 0.25 \mathrm{~mm}$ i.d.; df: $0.3 \mu \mathrm{m})$. Column 2: HTS-FS Carbowax $20 \mathrm{M}(25 \mathrm{~m} \times 0.25$ $\mathrm{mm}$ i.d.; df: $0.3 \mu \mathrm{m})$. Temperature program: from $50^{\circ} \mathrm{C}$ ( $\left.1 \mathrm{~min}\right)$ to $200^{\circ} \mathrm{C}(20 \mathrm{~min})$. Peak integrator: HP3393 Series II. Retention indices were identified by using, as reference, a mixture of the hydrocarbons C8-C25, which was analysed under the same conditions as used for the samples. In addition, $\alpha$ pinene, $\alpha$-3-carene, limonene, and $\alpha$-terpinene ( 1 $\mu \mathrm{L}$ each) were used as internal standard to identify the mean peaks of the chromatogram.

\section{Results}

Histologic and histochemical analyses of the roots

Root apparatus is a taproot system. The main root is a storage root with an abundant phloem (Figure 1A); it showed a multilayered periderm (Figure $1 A$ ), and the xylem appeared star-shaped in cross section, due to wide medullar rays. Lateral roots, less than $1 \mathrm{~mm}$ in diameter, showed a primary diarch structure (Figure 1B). In transverse section, two primary secretory ducts, on opposite sides, bounded by four epithelial cells, were visible in the pericycle (Figure 1C). Nadi reaction did not reveal terpenic compounds in the primary ducts. Lateral roots with a diameter of $1.5 \mathrm{~mm}$ showed a secondary structure with two secondary secretory ducts formed by cambium activity and located in the secondary phloem, on opposite sides (Figure 1D). These ducts were bounded by a uniseriate epithelium constituted by numerous secretory cells and had a large lumen containing terpenic compounds, stained in violet with the nadi reagent (Figure 1D). Due to secondary thickening of the root, the primary ducts, formed in the pericycle, had moved outwards and were located directly under the periderm (Figure 1E). Taproots of $4 \mathrm{~mm}$ in diameter had a greater quantity of, and larger-sized, secondary secretory ducts, which were aligned with the secondary xylem (Figure $1 \mathrm{G}$ ). In larger roots (at least $5 \mathrm{~mm}$ in diameter), the cortex, the primary phloem, and the outermost part of the secondary phloem were crushed, due to secondary thickening and to periderm formation, and the ducts immersed in these crushed tissues were compressed and dysfunctional. The innermost ducts of the secondary phloem had persisted and were both numerous and large. At this stage, the medullar rays were sinuous (Figure IF). The epithelial secretory cells that bounded the duct lumen, stained in violet by nadi reagent, are shown in Figures $I F$ and $1 G$. The ducts were not branched in the distal part of the root, though they were both branched and anastomosed in the most proximal part (Figure $1 \mathrm{H}$ ).

\section{Essential oils in the roots}

The comparison of the chromatograms obtained from the three samples of roots (i.e., lateral roots of 1-2 $\mathrm{mm}$ in diameter and taproots of 3-4 $\mathrm{mm}$ and greater than $5 \mathrm{~mm}$ ) showed that the more developed roots contained greater quantities of oils (Figures 2A, B, C). This was especially evident in 


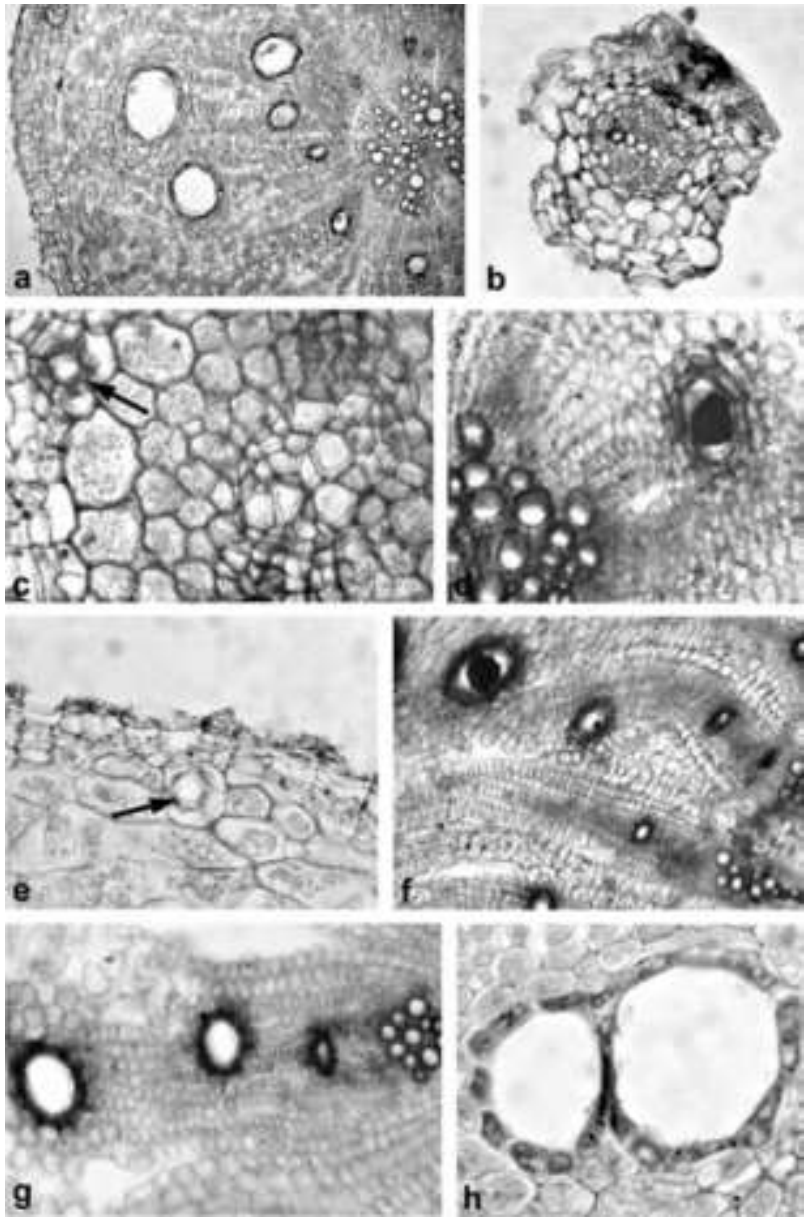

Figure 1. Micrographs of Angelica archangelica subsp. archangelica roots at different developmental stages. 1a. Cross-section of the taproot $(3 \mathrm{~mm}$ in diameter) showing a multi-layered periderm and some secondary ducts arranged in rows, located in the secondary phloem. The section is stained with methylene-green and ruthenium red $\times 33$. 1b. Cross-section of a lateral root $(0.5 \mathrm{~mm}$ in diameter) showing a primary diarch structure. The section is stained with methylene-green and ruthenium red $\times 70$. 1c. Cross-section of a lateral root $(0.8$ $\mathrm{mm}$ in diameter) stained with methylene-green and ruthenium red. A primary secretory duct (arrow) in the pericycle bounded by four epithelial cells is shown $\times 270$. 1 d. Cross-section of a fresh lateral root $(1.5 \mathrm{~mm}$ in diameter) showing secondary structure. A secondary duct bounded by a uniseriate epithelium is shown in the phloem. Terpenic compounds, stained in violet (black in the black and white figure) with nadi reagent, were visible in the duct lumen $\times 100$. 1e. Primary secretory duct directly under the periderm $\times 180$. 1f. Cross section of a fresh taproot (5 $\mathrm{mm}$ in diameter) stained with nadi reagent showing some secondary ducts in the phloem and sinuous medullar rays. $x$ 170. 1g. Cross section of a fresh taproot (4 mm in diameter) showing some secondary ducts aligned with the secondary xylem. Epithelial cells of the ducts are stained with nadi reagent $\times 170$. 1h. Secondary ducts anastomosed in the proximal part of the taproot. The section is stained with methylenegreen and ruthenium red $\times 180$.

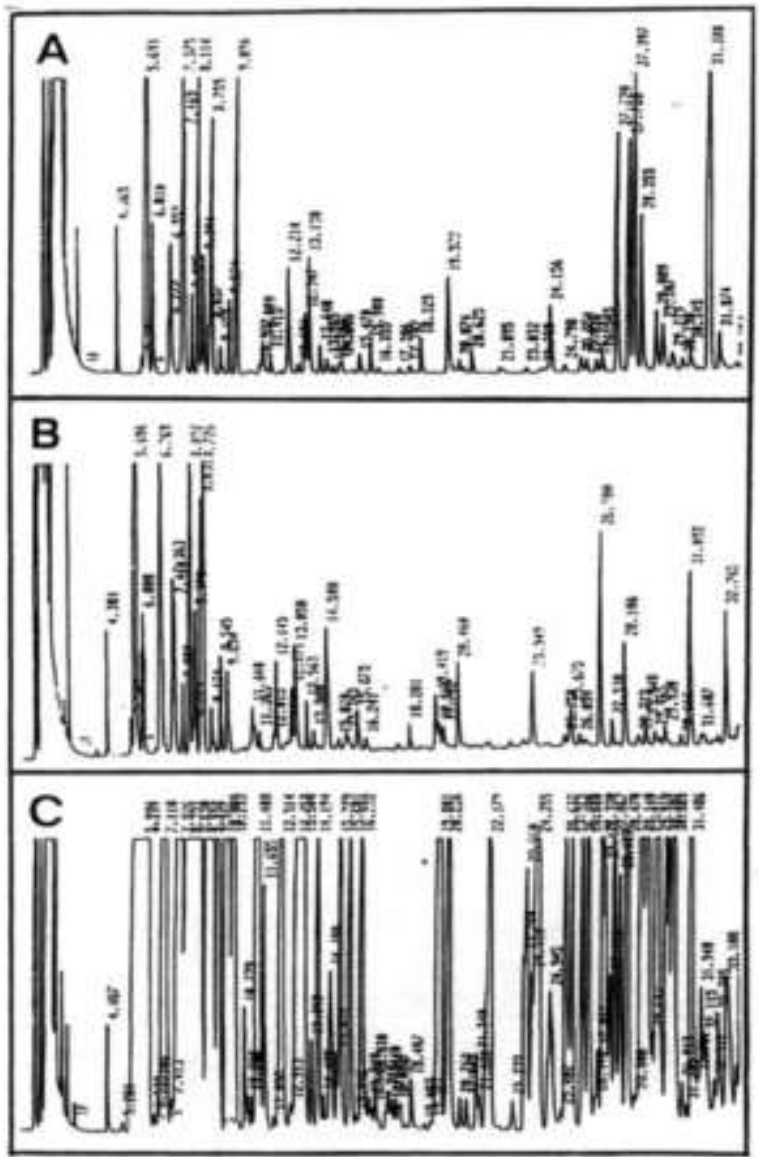

Figure 2. Gas chromatograms of the oils from samples of Angelica archangelica roots ( $3 \mathrm{~g}$ of fresh weight): $1-2 \mathrm{~mm}$ in diameter (A); 3-4 mm (B) and greater than $5 \mathrm{~mm}$ (C). Peaks are identified by numbers indicating the retention time.

the sample of roots greater than $5 \mathrm{~mm}$ (Figure 2 C), where the peak quantities were from 12 to 20 times higher than the corresponding peaks in the 1$2 \mathrm{~mm}$ sample (Figure $2 \mathrm{~A}$ ). The retention times and percentage areas of the peaks of the principal compounds are shown in Table 1. Most of the compounds identified were monoterpenes and, to a lesser extent, sesquiterpenes (from $\alpha$-copaene to $\alpha$ humulene epoxide).

Of the monoterpenes detected, $\alpha$-pinene was present in the greatest concentration, although consistent differences were observed between young roots and those at a more advanced stage of development (Table 1 ). Variations in concentration were also observed for $\alpha$ - and $\beta$-phellandrene, with values increasing with the maturity of the root (Table 1 ). 
Table 1. Retention times and percentage areas of the chromatogram peaks of principal compounds identified in roots (1-2 $\mathrm{mm}, 3-4 \mathrm{~mm}$, greater than $5 \mathrm{~mm}$ in diameter), taken from 15month-old Angelica archangelica plants.

\begin{tabular}{|c|c|c|c|c|}
\hline Compound & $\begin{array}{l}\text { Retention time } \\
\text { (min.) }\end{array}$ & $\begin{array}{c}\text { Area } \% \\
\text { root } 1-2 \mathrm{~mm}\end{array}$ & $\begin{array}{l}\text { Area } \% \\
\text { root 3-4 mm }\end{array}$ & $\begin{array}{c}\text { Area } \% \\
\text { root }>5 \mathrm{~mm}\end{array}$ \\
\hline Heptanale & 4.365 & 0.86 & - & - \\
\hline$\alpha$-thujene & 5.503 & 1.12 & - & 0.62 \\
\hline$\alpha$-pinene & 5.691 & 23.89 & 35.7 & 32.69 \\
\hline Camphene & 6.010 & 1.26 & 1.3 & 1.53 \\
\hline Sabinene & 6.772 & 0.35 & 7.0 & 0.92 \\
\hline$\beta$-pinene & 6.853 & 1.32 & 1.3 & 1.87 \\
\hline Octanal & 7.375 & 2.76 & 1.6 & - \\
\hline$\beta$-myrcene & 7.469 & 2.13 & 1.5 & 5.87 \\
\hline$\alpha$-phellandrene & 7.825 & 0.75 & 0.8 & 3.74 \\
\hline$\delta$-3-carene & 8.114 & 3.41 & 4.6 & 17.07 \\
\hline$\alpha$-terpinene & 8.225 & - & 0.3 & - \\
\hline p-cymene & 8.394 & 1.10 & 1.4 & 0.38 \\
\hline$\beta$-phellandrene & 8.657 & 0.35 & 2.3 & 3.43 \\
\hline Limonene & 8.755 & 2.43 & 3.6 & 6.59 \\
\hline Cis- $\beta$-ocymene & 9.155 & 0.24 & 0.4 & 1.80 \\
\hline Trans- $\beta$-ocymene & 9.574 & 0.67 & 1.0 & 4.83 \\
\hline$\gamma$-terpinene & 9.896 & 3.09 & 1.2 & 1.23 \\
\hline$\alpha$-terpinolene & 11.089 & 0.50 & 0.9 & 1.84 \\
\hline Trans-sabinene hydrate & 12.214 & 1.20 & - & 0.91 \\
\hline Terpinen-4-ol & 13.015 & - & 2.1 & - \\
\hline 2-decenal & 18.325 & 0.36 & - & - \\
\hline Bornyl acetate & 19.572 & 1.33 & 0.8 & 1.37 \\
\hline Trans-sabinyl acetate & 20.460 & - & 0.4 & - \\
\hline$\alpha$-copaene & 24.350 & 0.85 & 1.1 & 1.32 \\
\hline$\alpha$-humulene & 27.220 & 3.21 & 3.1 & 0.38 \\
\hline Trans- $\beta$-pharnesene & 27.760 & 2.65 & 0.3 & 0.26 \\
\hline Germacrene D & 28.355 & 2.10 & 1.5 & 0.47 \\
\hline$\alpha$-humulene epoxide & 33.044 & 0.13 & 2.0 & - \\
\hline
\end{tabular}

\section{Discussion}

The results of this histochemical and chemical study show that, in Angelica archangelica subsp. archangelica, only taproots with a diameter greater than $5 \mathrm{~mm}$ reach their full capacity of oil-biosynthesis, in terms of both the pattern and concentration of metabolites. This capacity is correlated with the differentiation of secondary secretory ducts, which are large and bounded by numerous secretory cells. Primary ducts do not accumulate essential oils and are ephemeral.

Primary and secondary ducts have also been described for other species of Apiaceae (Deutschmann, 1969). Although, in Angelica archangelica secretory ducts differentiate in all of the plant's organs (Metcalfe and Chalk 1950), we observed that secondary ducts in the root were greater in both number and size.

The chromatographic analyses revealed that roots at different developmental stages varied in terms of the quantity and composition of oils. Only roots exceeding $5 \mathrm{~mm}$ in diameter contained a high concentration of $\alpha$ - and $\beta$-phellandrene, which, together with pinenes, are responsible for the oil's aroma. The quantity of these components is also important for the aroma of the oil, so that in ancient times (Tschirsch, 1917) Angelica archangelica was regarded as a phellandrene drug. Moreover, oils in which the concentration of phellandrene is greater than that of pinenes are considered better for obtaining the angelica-like aroma (Forsén, 1979).

\section{Acknowledgements}

This research was supported by funds (contribution no. 96.00454.CT06) from the National Research Council (C.N.R.) of Italy.

\section{References}

Bicchi C, D'Amato A, Nano GM, Frattini C. Improved method for the analyses of small amounts of essential oils by microdistillation followed by capillary gas-chromatography. J Chromatography 1983; 273:409-16.

David R, Carde JP. Coloration différentielle des inclusions lipidiques et terpéniques des pseudophylles du $P$ in maritime au moyen du réactif nadi. C R Acad Sci Paris Groupe 1964;13:1338-40.

Deutschmann F. Anatomische Studien über die Exkretgänge in Umbelliferenwurzeln. Beitr Biol Pflanzen 1969;45:409-40.

Doneanu C, Anitescu G. Supercritical carbon dioxide extraction of Angelica archangelica L. root oil. J Supercrit Fluid 1998;12:59-67.

Forsén K. Aroma constituents of Angelica archangelica. Variation in the composition of the essential root oil of strains of var. norvegica and var. sativa. Rep Kev Subart Res Stat 1979;15:1-7.

Johansen DA. Plant microtechnique. McGraw-Hill Book Co., 1940.

Kerrola K, Galambosi B, Kallio H. Characterization of volatile composition and odor of angelica (Angelica archangelica subsp. archangelica L.) root extracts. J Agric Food Chem 1994;42:1979-88.

Kerrola K, Kallio H. Extraction of volatile compounds of angelica (Angelica archangelica L.) root by liquid carbon dioxide. J Agric Food Chem 1994;42:2235-45.

Klouwen $\mathrm{MH}$, Ter Heide R. Studies on terpenes II. The monoterpene hydrocarbon composition of the volatile oil of Angelica archangelica L. (Umbelliferae). Perfum Essent Oil Rec 1965;56:224-8.

Metcalfe CR, Chalk L. Anatomy of the dicotyledons. Oxford, UK: Clarendon Press; 1950. p. 712-24.

Nykänen I, Nykänen L, Alkio M. Composition of angelica root oils obtained by supercritical C02 extraction and steam distillation. J Essent Oil Res 1991;3:229-36.

Taskinen J, Nykänen L. Chemical composition of angelica root oil. Acta Chem Scand B 1975;29:757-64.

Tschirsch A. Handbuch der Pharmakognosie II. Leipzig 1917. p. 1625. 